\title{
HYDROTHERMAL SYNTHESIS AND CHARACTERIZATION OF ZnO, MgO AND ZnO/MgO NANOCOMPOSITES
}

\author{
S. Bhuvaneshwari ${ }^{1}$, S. Satheeskumar ${ }^{2, ®}$, Jeevanantham Velayutham $^{3}$ \\ and Bavaji Syed Rahman ${ }^{4}$ \\ ${ }^{1}$ Department of Physics, KPR Institute of Engineering and Technology, Coimbatore -641407, \\ Tamilnadu, India \\ ${ }^{2}$ Department of Nanoscience and Technology, K.S. Rangasamy College of Technology, \\ Tiruchengode - 637 215, Tamilnadu, India \\ ${ }^{3}$ Department of Chemistry, Vivekanandha College of Arts and Sciences for \\ Women(Autonomous), Tiruchengode - 637215, Tamilnadu, India \\ ${ }^{4}$ Research Scholar, PG and Research Department of Chemistry, Jamal Mohamed College \\ (Autonomous) Tiruchirappalli-620 020, Tamilnadu, India \\ ${ }^{\square}$ Corresponding Author: satheesphysics@gmail.com
}

\begin{abstract}
Nano Zinc oxide $(\mathrm{ZnO})$ with different morphologies including spherical-like, granular shapes, have been hydrothermally synthesized at low temperature at $100^{\circ} \mathrm{C}$ using stainless steel autoclave. It was found that the volumes of added Sodium hydroxide and Zinc acetate dihydrate in water play a crucial role in the morphological control of $\mathrm{ZnO}$ nanostructure. Based on structural information provided by FTIR, XRD and SEM, a possible growth mechanism for the formation of spherical $\mathrm{ZnO}$ structures was discussed. The optical properties of the synthesized nanoparticles were studied by Ultraviolet-visible spectroscopy and strong absorption peaks at $279 \mathrm{~nm}$ for all synthesized nanoparticles. From that study, the band gap was also calculated and it was 3.79, 3.64 and $3.55 \mathrm{eV}$ respectively for $\mathrm{ZnO}, \mathrm{MgO}$ and $\mathrm{ZnO} / \mathrm{MgO}$ nanocomposites. Nanoparticles of $\mathrm{MgO}$ are prepared by using the sol-gel route. The $\mathrm{MgO}$ nanograins were sphere-like and needle-like and had a large surface area. The grain size was obtained using XRD data. The X-ray diffraction patterns revealed the formation of nanoparticles of $\mathrm{MgO}$. The structural morphology and optical properties of the nanoparticles were studied using SEM. The formation of the nanostructure is confirmed using FTIR. A process was proposed for the synthesis of $\mathrm{ZnO} / \mathrm{MgO}$ nanocomposites using sol-gel preparation of $\mathrm{ZnO}$ and magnesium with an alkali solution following by annealing in the range of $400^{\circ} \mathrm{C}$. X-ray powder diffraction showed crystalline $\mathrm{ZnO}$ and $\mathrm{MgO}$ phases in the resulting composite. The zinc oxide nanoparticle size was weakly affected by the molar ratio of zinc to magnesium.
\end{abstract}

Keywords: $\mathrm{ZnO}, \mathrm{MgO}$, XR-D, FT-IR, Hydrothermal, Nanocomposites

RASĀYAN J. Chem., Vol. 14, No.3, 2021

\section{INTRODUCTION}

The optimum preparation of nanoparticles was perilous for the production of nanotechnologies regarding the shape and size. Particularly $\mathrm{Zn}-\mathrm{O}$ nano-systems, such as nanowires, nanobelts and thin-films can be simply shaped by physical or chemical methods such as chemical vapor deposition, pulsed laserdeposition, sol-gel process, thermal-annealing method and solvothermal analysis. $\mathrm{Zn}-\mathrm{O}$ has polar surfaces that help in the production of a wide range of nanomaterials such as nanowires, nanobelts and thin-films rings, springs, bows and helices. ${ }^{1} \mathrm{Zn}-\mathrm{O}$ has established substantial care since of its unique optical, semiconducting, piezo-electric and magnetic properties. Zn-O nanostructures show remarkable properties such as large catalytic effect and sturdy adsorption capacity. The array of morphologies such as rods, tubes, rings, tetra-pods, spirals is the field of $\mathrm{Zn}-\mathrm{O}$ that produces the base of its versatile applications. $\mathrm{MgO}$ has spacious structures, which can carry a great deal of effective catalytic compositions to form a carrier compound catalyst. Based on the technology for the preparation of $\mathrm{Nano} \mathrm{MgO}$, a new technology to produce nano- $\mathrm{MgO}$ under simple conditions. Alkaline earth metal-oxides are well known for their fundamental characteristics. Although $\mathrm{Mg}-\mathrm{O}$ displays the most fundamental characteristics of this group, 
no acid property have ever been inspected in detail. ${ }^{2} \mathrm{Zn}-\mathrm{O} / \mathrm{Mg}-\mathrm{O}$ nanoparticles can be used as the photocatalyst for the degradation of effluents, electrode nanomaterials in super-capacitor, antibacterial agent and microwave absorbing materials. Numerous skills for synthesizing $\mathrm{Zn}-\mathrm{O}$ and $\mathrm{Mg}-\mathrm{O}$ nanomaterials have been described, like alkoxide-hydrolysis, gas-phase thermal-decomposition, core-sheath and microemulsion technologies. ${ }^{3}$

\section{Preparation of Nano- $\mathrm{ZnO}$}

\section{EXPERIMENTAL}

$0.5 \mathrm{~g}$ of zinc acetate dehydrate $\mathrm{Zn}\left(\mathrm{CH}_{3} \mathrm{COO}\right)_{2} .2 \mathrm{H}_{2} \mathrm{O}$ were dissolved in $110 \mathrm{ml}$ of deionized water under 10 mins vigorous stirring. Subsequently, the dissimilar solution, $10 \mathrm{ml}$ of Sodium hydroxide (2 molars) was presented in it, resultant in a slurry white-precipitate produced. Afterward, five mins stirring, the solution was transported into a stainless-steel auto-clave of $200 \mathrm{ml}$ volume and closed. The auto-clave was continued at $100^{\circ} \mathrm{C}$ for $5 \mathrm{hrs}$ and cooled in the air at room temperature. The resultant colorless products were centrifuged, cleaned then rinsed with dehydrated water and ethyl alcohol many times to eliminate the ions probably residual in the last product and dried at $70^{\circ} \mathrm{C}$ in air.

\section{Preparation of Nano-MgO}

Magnesium chloride $(0.5 \mathrm{~mol})$ and sodium carbonate $(0.5 \mathrm{~mol})$ were dissolved in $100 \mathrm{ml}$ deionized water separately. Under room temperature, the $100 \mathrm{ml}$ of $\mathrm{Na}_{2} \mathrm{CO}_{3}$ solution was slowly added to the $\mathrm{MgCl}_{2}$ solution with stirring to obtain $\mathrm{MgCO}_{3} \cdot 3 \mathrm{H}_{2} \mathrm{O}$. After the vigorous stirring, the products were transferred into a Teflon-lined stainless steel autoclave. Sealed and hydrothermally treated at a constant temperature of $60^{\circ} \mathrm{C}$. The products were aged for 3 to $96 \mathrm{~h}$. After filtration, the precipitated particles were washed with distilled water and ethanol several times and drying the products were calcined for 2 hours at $200^{\circ} \mathrm{C}$ to get nano $\mathrm{MgO}$.

\section{Preparation of Nano- $\mathrm{ZnO} / \mathrm{MgO}$ composites}

Solutions were prepared by dissolving $0.5 \mathrm{~g}$ of zinc acetate dihydrate in $110 \mathrm{ml}$ of dehydrated water under 600 seconds by forceful stirring. Formerly $10 \mathrm{ml}$ of sodium hydroxide $(2 \mathrm{M})$ solution was added into that solution and the solution is kept at $100{ }^{\circ} \mathrm{C}$ for $5 \mathrm{hrs} . \mathrm{MgCl}_{2}(0.5 \mathrm{~mol})$ and $\mathrm{Na}_{2} \mathrm{CO}_{3}(0.5 \mathrm{~mol})$ were dissolved in $100 \mathrm{ml}$ deionized water. These two solutions were slowly mixed to get $\mathrm{MgCO}_{3} .3 \mathrm{H} 2 \mathrm{O}$ and this solution was added to the first solution in drop-wise and dried at $150^{\circ} \mathrm{C}$ to get $\mathrm{ZnO} / \mathrm{MgO}$ nanocomposite.

\section{ZnO NPs}

\section{RESULTS AND DISCUSSION}

The X-Ray Diffraction spectra of the synthesized nanomaterials are shown in Fig.-1. All the diffraction peaks are confirmed with JCPDS- No 361451, which can be indexed to the structure of hexagonalwurtzite $\mathrm{Zn}-\mathrm{O}$. The strong, sharp peaks specify that the $\mathrm{Zn}-\mathrm{O}$ nanomaterials were well crystallized. The nano-size of the nanoparticles was determined by following Debye-Scherrer's formula.

$$
\mathrm{D}=0.9 \lambda / \beta \cos \theta
$$

From the eqn.-1, Where $\mathrm{D}$ is crystallite-size, $\lambda$ is the $\mathrm{X}$-ray-wavelength, $\beta$ is the full-width at half maximum (FWHM) and $\theta$ the half diffraction angle. The nanosize of the synthesized nanomaterials calculated using FWHM.

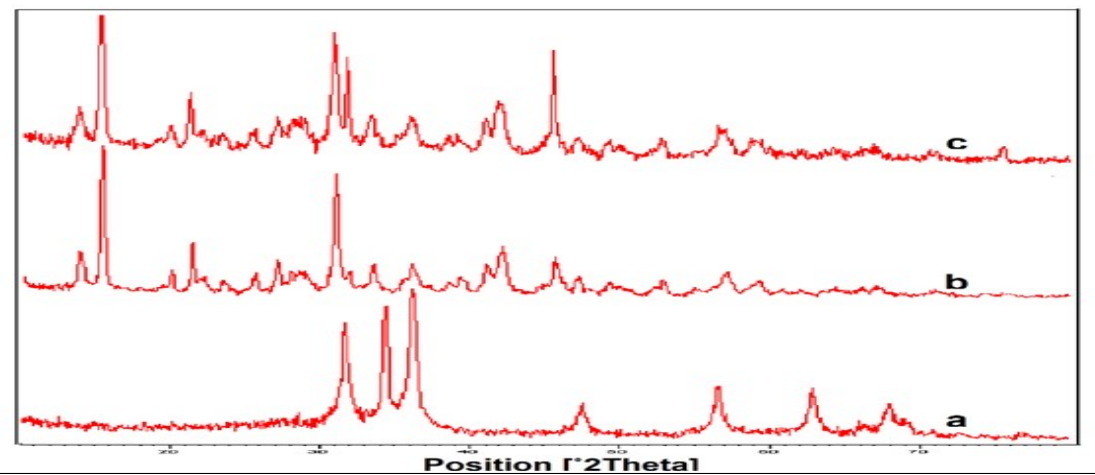

Fig.-1: The $\mathrm{XRD}$ pattern of synthesized (a) nano $\mathrm{ZnO}$ (b) nano $\mathrm{MgO}$ and (c) $\mathrm{ZnO} / \mathrm{MgO}$ Nanocomposites 
RASĀYAN J. Chem.

Vol. 14 | No. 3 |1581-1586| July - September | 2021

Table-1: Particle Size estimated from the Diffraction Spectrum of $\mathrm{ZnO}, \mathrm{MgO}$ and $\mathrm{ZnO} / \mathrm{MgO}$ by using full width half maximum (FWHM)

\begin{tabular}{c|c|c|c|c}
\hline NPs & $\begin{array}{c}\text { Pos. } \\
\text { [ } 2 \text { Th.] }\end{array}$ & $\begin{array}{c}\text { FWHM } \\
{\left[{ }^{\circ} 2 \text { Th.] }\right.}\end{array}$ & $\begin{array}{c}\text { d-spacing } \\
{[\AA]}\end{array}$ & $\begin{array}{c}\text { Particle } \\
\text { size }\end{array}$ \\
\hline \multirow{5}{*}{$\mathrm{ZnO}$} & 20.6070 & 0.1624 & 4.30666 & \\
& 21.1017 & 0.3767 & 4.20680 & 49.75 \\
& 31.7168 & 0.2223 & 2.81892 & 21.46 \\
& 32.2752 & 0.2204 & 2.77141 & 37.17 \\
& 36.2111 & 0.3289 & 2.47869 & 37.55 \\
& 37.8471 & 0.1952 & 2.37522 & 25.43 \\
& 39.4328 & 0.2219 & 2.28328 & 43.05 \\
& 40.2274 & 0.2581 & 2.23999 & 38.05 \\
& 46.2716 & 0.3002 & 1.96049 & 30.82 \\
& 47.5163 & 0.3934 & 1.91199 & 28.79 \\
& 51.9470 & 0.3629 & 1.75885 & 22.08 \\
& 61.5732 & 0.3442 & 1.50496 & 24.37 \\
& & & & 26.88 \\
\hline \multirow{5}{*}{$\mathrm{MgO}$} & 15.4289 & 0.2689 & 5.73839 & 29.83 \\
& 21.3730 & 0.2720 & 4.15400 & 29.74 \\
& 23.4882 & 0.5796 & 3.78450 & 14.01 \\
& 25.5503 & 0.4588 & 3.48354 & 17.76 \\
& 27.0762 & 0.5220 & 3.29059 & 15.66 \\
& 30.9597 & 0.4331 & 2.88610 & 19.04 \\
& 33.4133 & 0.4854 & 2.67957 & 17.10 \\
& 39.2598 & 0.5674 & 2.29294 & 14.87 \\
& 41.0206 & 0.6017 & 2.19850 & 14.10 \\
& 47.1339 & 0.4798 & 1.92661 & 18.08 \\
\hline \multirow{5}{*}{$\mathrm{MnO} / \mathrm{MgO}$} & 15.3311 & 0.3657 & 5.77478 & 21.93 \\
& 21.2522 & 0.3312 & 4.17735 & 24.42 \\
& 45.4803 & 0.3462 & 1.99274 & 24.90 \\
& 75.3208 & 0.3428 & 1.26076 & 29.29 \\
\hline
\end{tabular}

Characteristic FT-IR spectra of Zn-O were revealed in Fig.-2, in which the peak at $3403 \mathrm{~cm}^{-1}$ was assigned to the $\mathrm{O}-\mathrm{H}$ stretching vibration. Symmetric $\mathrm{C}=\mathrm{O}$ stretching of zinc acetate dehydrate at $1543 \mathrm{~cm}^{-1}$, $\mathrm{C}-\mathrm{H}$ out-of-plane bending group at $898-865 \mathrm{~cm}^{-1} \mathrm{O}-\mathrm{H}$ bending of hydroxyl group at $558 \mathrm{~cm}^{-1}$ and $\mathrm{ZnO}$ stretching of $\mathrm{ZnO}$ at $420 \mathrm{~cm}^{-1}{ }^{4}$ Figure-3(a, b, c) shows the SEM images of the synthesized nanoparticles. From the figure. one can observe that the products are mainly composed of spherical nanostructures. From Fig.-3(b) displays some imperfect micro-spheres also exist in the products are observed in $5 \mu \mathrm{m}$. The $\mathrm{ZnO}$ nanoparticles have spherical structures. In SEM figure $(1 \mu \mathrm{m}$ and $500 \mathrm{~nm})$ a large number of granular shapes are found.

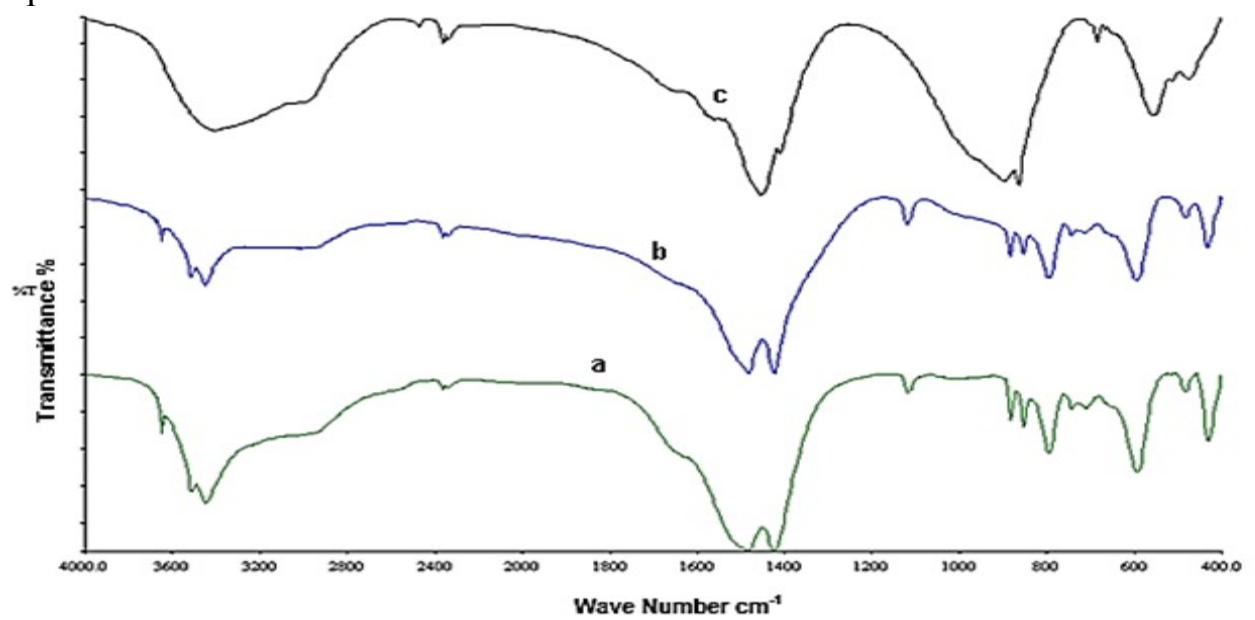

Fig.-2: FT-IR Spectrum of synthesized (a) nano $\mathrm{ZnO}$ (b) nano $\mathrm{MgO}$ and (c) $\mathrm{ZnO} / \mathrm{MgO}$ Nanocomposites 1583 


\section{MgO NPs}

$\mathrm{MgCl}_{2}$ solution reacts with $\mathrm{Na}_{2} \mathrm{CO}_{3}$ solution to produce $\mathrm{MgCO}_{3} \cdot 3 \mathrm{H}_{2} \mathrm{O}$, if the reaction temperature is high, it would favor forming a large number of the core in a short time. It makes the cores do not have enough time to grow up. So, $\mathrm{MgCO}_{3} .3 \mathrm{H}_{2} \mathrm{O}$ in larger size could not be obtained, this is unfavorable to the further reaction to getting $\mathrm{MgO}$. The aging time also affects the grain size of $\mathrm{MgCO}_{3} \cdot 3 \mathrm{H}_{2} \mathrm{O}$. The axis and length of $\mathrm{MgCO}_{3} .3 \mathrm{H}_{2} \mathrm{O}$ were increased as the aging time was prolonged. $\mathrm{MgO}$ showed amorphous X-ray diffraction patterns as reported by Bokhimi et al., 1995, where the evaluation of the crystalline structure is chiefly related to the calculations hours. All diffraction peaks of $\mathrm{MgO}$ could be indexed as the hexagonal structure (Fig.-1b) confirmed by JCPDS card No 40829. From X-Ray Diffraction, peaks arising from impurities were spotted. Therefore, the preparation phase agrees to pure $\mathrm{MgO}$, suggesting a comprehensive synthesis reaction. Total development of the intensity of the XRD peaks is a visible, indication that the upsurge in crystallinity of nanomaterials after hydro-thermal reaction ${ }^{6}$. The particle size of nano $\mathrm{MgO}$ was $19.01 \mathrm{~nm}$. Figure-2(b) shows infrared spectra of $\mathrm{MgO}$. Characteristic $\mathrm{MgO}$ hydroxyl stretching vibration bands are observed at 3689-3629 $\mathrm{cm}^{-1}$. The absorption bands due to $\mathrm{CH}_{2}$ bending and symmetric C-O-C stretching of $\mathrm{MgO}$ at 1483 and $1120 \mathrm{~cm}^{-1}$. C-C out of the plane and C-H bending vibration of $\mathrm{MgO}$ at 715 and $668 \mathrm{~cm}^{-1}$. The SEM micrograph in Fig.-3(a, b, c) demonstrates that, during magnesium chloride calcination at $200^{\circ} \mathrm{C}$, the globular-like structure of the particles persists in 10 $\mu \mathrm{m}$. Even though it is a non-equilibrium shape for $\mathrm{MgO}$ was observed for $4 \mu \mathrm{m}$ and $2 \mu \mathrm{m}$ (Fig.-1). At 2 $\mu \mathrm{m}$ the irregular flake-like structures were observed.

\section{$\mathrm{ZnO} / \mathrm{MgO}$ NPs}

The X-ray diffraction pattern of the nanocomposite is presented in Fig.-1(c). The peaks at $21.10^{\circ}$ and $51.94^{\circ}$ are attributed to standard diffraction of wurtzite $\mathrm{ZnO}$ peaks and also cubic $\mathrm{MgO}$ peaks at 75.32 in the detection limit. The MgO structure (with Miller indices 111, 110, 102, (JCPDS card No 74-1225) and those associated with zinc oxide (Wurtzite indices 100, 002, 101 and 110 (JCPDS card no 79-205). The unit cell parameters for $\mathrm{MgO}$ and $\mathrm{ZnO}$ phases almost coincide with the literature values. This means that, there are no noticeable interactions between the magnesium and zinc oxides at this low annealing temperature. In this work, the effect of concentration of the precipitated component and the zinc-tomagnesium molar ratio on the zinc oxide nanoparticle size. ${ }^{7}$

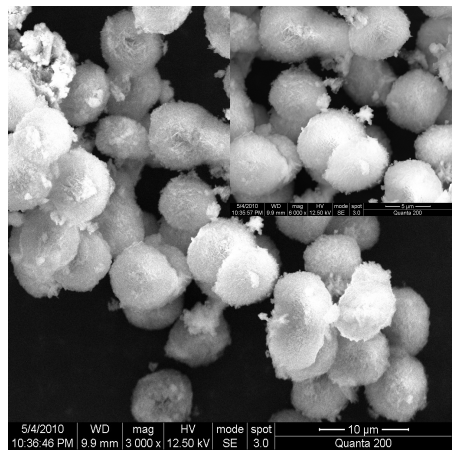

(a)

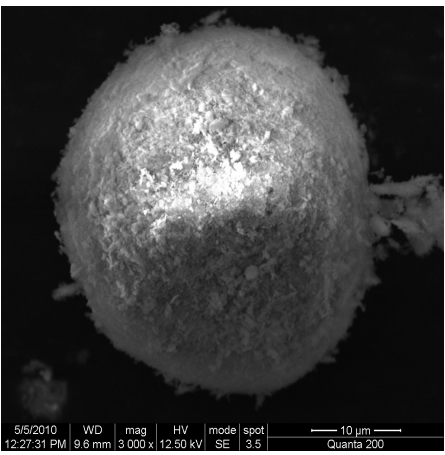

(b)

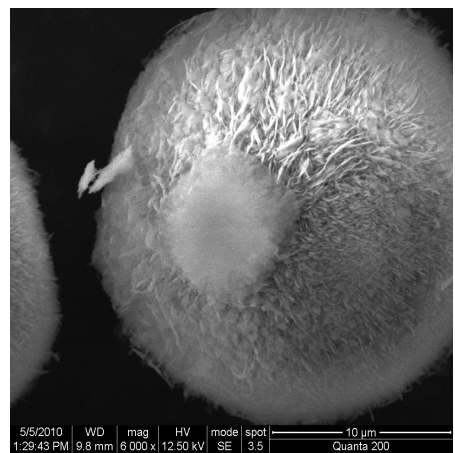

(c)

Fig.-3: SEM images of $\mathrm{ZnO}$ (a), $\mathrm{MgO}$ (b) and $\mathrm{ZnO} / \mathrm{MgO}$ (c) Nanocomposites

There are no systematic variations in the crystallite size as a function of that treatment. This result indicates the co-existing of $\mathrm{ZnO}$ and $\mathrm{MgO}$ in the composites. ${ }^{8,9}$ The X-ray diffraction patterns of the corresponding composite in Fig.-1c indicate that besides $\mathrm{ZnO}$, there still exists zinc acetate dehydrate and magnesium chloride. This fact indicates that the nanocomposites are not a single phase but a composite. The particle size of $\mathrm{ZnO} / \mathrm{MgO}$ nanocomposites was $25.13 \mathrm{~nm} .{ }^{10}$ Figure-2 shows the infrared spectra for $\mathrm{ZnO} / \mathrm{MgO}$ nanocomposites. The spectra are more similar to those of $\mathrm{MgO}$. The pronounced peaks at 3628 $\mathrm{cm}-1$ are also observed in $\mathrm{ZnO} / \mathrm{MgO}$ and suggest that the surface may be composed mainly by $\mathrm{MgO}$. The symmetric $\mathrm{C}=\mathrm{O}$ stretching of $\mathrm{ZnO}$ at $1635 \mathrm{~cm}^{-1}$. The hydroxyl bands at around $1500 \mathrm{~cm}-1$ also support this hypothesis. ${ }^{11}$ The coverage of $\mathrm{ZnO}$ particles by $\mathrm{MgO}$ can be observed by SEM. A typical SEM micrograph in Fig.-3(a, b, c) shows the several nanospheres connected. When comparing the micrograph 
of $\mathrm{ZnO}$ and $\mathrm{MgO}$, one may suggest, by observing the particles morphologies, shows a $\mathrm{ZnO}$ particle with small $\mathrm{MgO}$ ones located around it. The $\mathrm{MgO}$ particles are tightly attached since an electrostatic interaction between $\mathrm{ZnO}$ and $\mathrm{MgO}$ is expected. Figure-3(a) reinforces this hypothesis showing a micrograph using lower magnification to observe a larger number of particles. Note that the surface of the observed particle is rough (and not smooth as $\mathrm{MgO}$ particles) in Fig.-3(b) probably due to the adhesion of the smaller porous $\mathrm{MgO}$ particles on the surface of $\mathrm{ZnO}$. The inset of Fig.-3(c) indicates that the nanospheres grown on the inside surface of the sphere appear to be needle-like, and their diameters decrease from the root to the tip. ${ }^{12}$ Figure-4 evinces the Ultraviolet-visible spectroscopy of the nano $\mathrm{ZnO}$, nano $\mathrm{MgO}$ and $\mathrm{ZnO} / \mathrm{MgO}$ nanoparticles. From this, all spectra show that strong absorption peaks at 279 $\mathrm{nm}$, which is accredited to the absorption in $\mathrm{ZnO} / \mathrm{MgO}$ nanoparticles. From that data, the optical band gap $(\mathrm{Eg})$ of the synthesized nanoparticles can be calculated using the below equation:

$$
\alpha h v=\mathrm{C}(\mathrm{h} v-\mathrm{Eg}) \mathrm{n}
$$

Where $\alpha$-absorption coefficient, hv - Photon energy, C - Constant and $n=1 / 2$ for a directly allowed transition and it was 3.79, 3.64 and $3.55 \mathrm{eV}$ respectively, which are good agreement with conveyed of $\mathrm{ZnO} / \mathrm{MgO}$ nanoparticles band gap values.

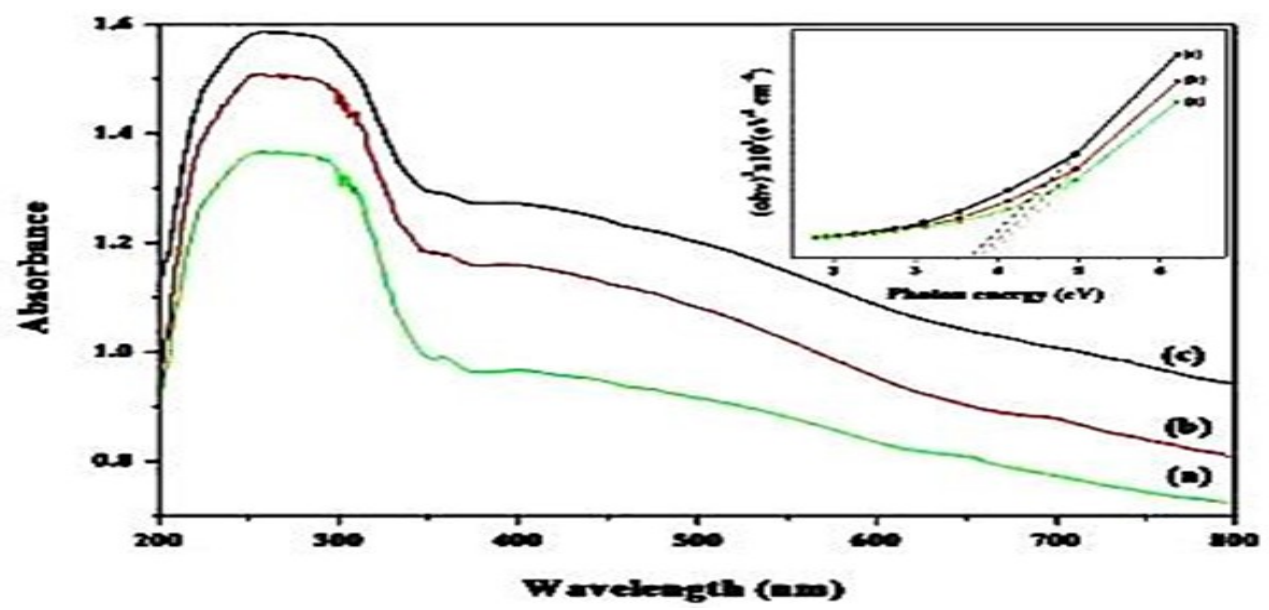

Fig.-4: UV-Visible Spectroscopy of of nano $\mathrm{ZnO}$ (a), nano $\mathrm{MgO}$ (b) and (iii) $\mathrm{ZnO} / \mathrm{MgO}$ (c) nanoparticles

\section{CONCLUSION}

In summary, a simple hydrothermal technique without the addition of any surface-active agent and polymers was put forward to prepare Zinc oxide nanocomposites. A uniform Zn-O nanosphere is detected from several magnifications $10 \mu \mathrm{m}, 5 \mu \mathrm{m}, 4 \mu \mathrm{m}$, and $3 \mu \mathrm{m}$. The aforementioned is the hydrothermal process zinc-acetate dihydrate reacted with sodium hydroxide to produce a complex, and the complex gradually disintegrated in the hydro-thermal process. All these features are promising to this condimentsfree hydro-thermal development of $\mathrm{ZnO}$ nanocomposites. The preparation route to Zinc Oxide nanoparticles was capable of enormous scale and cheapest method of production of $\mathrm{Zn}-\mathrm{O}$ nanomaterial. A technique is developed for the synthesis of $\mathrm{MgO}$ nanocomposites via $\mathrm{MgCl}_{2}$ and $\mathrm{Na}_{2} \mathrm{CO}_{3}$ form a solution. The particle shape is shown to persist during magnesium chloride conversion to magnesium oxide. The calculations hour is too high, the products would be easily sintered and the surface area and activity of $\mathrm{MgO}$ would be declined. The $\mathrm{ZnO} / \mathrm{MgO}$ nanocomposites are successfully produced by the hydrothermal process. The XRD patterns show the hexagonal phase of $\mathrm{ZnO}$ and the cubic phase of $\mathrm{MgO}$. The sizes and the morphology of $\mathrm{ZnO}$ spheroidal and hexagonal particles were found to be from 21.46-49.75 nm, whereas those of $\mathrm{MgO}$ spheroidal and flake (or) rectangular particles are in the range of 14.10-29.83 $\mathrm{nm}$. $\mathrm{ZnO}$ and $\mathrm{MgO}$ nanocomposites are found to approximately $21.93-29.29 \mathrm{~nm}$.

\section{ACKNOWLEDGEMENT}

We thank Vivekanandha College of Arts and Sciences for Women, Tiruchengode for providing lab facilities to perform the studies. This work is supported by the Management, KPR Institute of Engineering and Technology, Coimbatore and, Tiruchengode. 
RASĀYAN J. Chem.

Vol. 14 | No. 3 |1581-1586| July - September | 2021

\section{REFERENCES}

1. S. Basavaraj, Devaramani, Y. S. Ramaswam, A. Babu Manjasetty, T. R. Gopalakrishnan Nair, International Conference on Frontiers in Chemical Research, 18, 206(2010).

2. K. G. Kalogiannis, S. D. Stefanidis, S. A. Karakoulia, K. S. Triantafyllidis, H. Yiannoulakis C. Michailof, A. A. Lappas, Arabian Journal of Chemistry, 12, 4897(2019), https://doi.org/10.1016/j.apcatb.2018.07.016

3. Muzammil Anjum, R. Miandad, Muhammad Waqas, F. Gehany, M. A. Barakat, Applied Catalysis B: Environmental, 15, 346(2018), https://doi.org/10.1016/j.arabjc.2016.10.00

4. S. Kanchana, Suhashini Ernest, K. Pushpanathan, Journal of Luminescence, 176, 6(2016), https://doi.org/10.1016/j.jlumin.2015.12.047

5. A. Bokhimi, T. Morales, R. Lopez, Gomez, Journal of Solid State Chemistry, 2, 411(1995), https://doi.org/10.1006/jssc.1995.115210

6. Roger Ibbett, Sanyasi Gaddipati, Sandra Hill, and Greg Tucker, Biotechnol Biofuels, 6,33 (2013),

7. N. Baranov, O. O. Kapitanova, G. N. Panin and T. V. Kang, Russian Journal of Inorganic Chemistry, 53, 1366(2008).

8. Alia Servin, Wade Elmer, Arnab Mukherjee, Roberto De la Torre-Roche, Helmi Hamdi, Jason C. White, Prem Bindraban \& Christian Dimkpa, Journal of Nanoparticle Research, 17, 92(2015)

9. B. Marí K. C. Singh N. Verma J. Jindal, Ceramics International, 42, 13018(2016), https://doi.org/10.1016/j.ceramint.2016.05.079

10. Saba A. Mahdy, Engineering \&Technology Journal, 34(1), 65(2016).

11. Abinash Das, S. Nikhil, K. Ranjith, G. Nair, Nano-Structures \& Nano-Objects, 19, 100353(2019), https://doi.org/10.1016/j.nanoso.2019.100353

12. S. Satheeskumar, V. Jeevanantham, D. Tamilselvi, Journal of Ovonic Research, 14, 9(2018)

13. V. Jeevanantham, K. Hemalatha, S. Satheeskumar, Journal of Ovonic Research 14, 269(2018)

14. R. Kannan, S. Ganesan, and T. M. Selvakumari, Digest Journal of Nanomaterials and Biostructures, 7(3), 1039 (2012).

[RJC-6022/2020] 